\title{
The Application of Jurisprudence and the Construction of Legal Discourse System
}

\author{
Jie He \\ Kunming University, School of Social Management, Kunming, Yunnan, 650214
}

Keywords: jurisprudence; construction; Legal Discourse System

\begin{abstract}
The jurisprudence has always been an important issue for legal scholars. However, for many years, the research on the role or function of jurisprudence has not been detailed. Although the function of jurisprudence can be carried out from both the perspectives of legislation and judicature, most scholars explore the political function of jurisprudence from the perspective of legislation. The jurisprudential function of the legislative perspective mainly focuses on the political function of jurisprudence, more about borrowing the discourse system of current affairs politics and the link of legal discourse, and interpreting political discourse from the perspective of jurisprudence.
\end{abstract}

\section{Introduction}

There are several reasons why the "use of jurisprudence" or the argumentative theory of science has become a problem. The main ones include: First, there is a lack of methodological content in the knowledge structure of most jurisprudence textbooks. Many of the texts in the textbooks are law-centered. Position, there is little talk about the law of justice and law enforcement. Did not regard the understanding, interpretation and use of the law as the key to teaching; did not improve the level of legal thinking as the main goal and key content of teaching. This makes the practicality that jurisprudence itself should not show. Second, the reason why the theory of jurisprudence is useless is, to a certain extent, related to the research position of jurisprudence and the narrative methods of professors. The legal system of Chinese jurisprudence mainly comes from the West. Jurisprudence in the West is mainly a description of the judicial and law-enforcement processes. However, the meaning of the original description of the judicial process has changed subtly since it was introduced to China, or it has become unsuccessful. The explanation of knowledge has either been transformed into the concept of a legislative position. Such as law, the rule of law, legal sources, legal relations, legal systems, etc. are all taught as general legal knowledge. As a result, the knowledge system of jurisprudence has become the accumulation of legal basic knowledge. Even descriptions of legal methods, legal interpretations, legal reasoning, etc. are only taught as knowledge. Students do not learn the techniques or methods used by the law, and their legal skills are not improved. Third, when the jurists of the forerunners built the jurisprudence system, they were greatly influenced by the Soviet jurisprudence and had a strong sense of political mission. This made the basic structure of the disciplines have a strong class color and introduced a large amount of political discourse. The consideration of the state power has strengthened the dependence of the law on state power and state coercive power, and the independence of the law and the constraints on the state power have not been demonstrated. This means that China's jurisprudence lacks strategic thinking on the path or method of achieving the rule of law. While strengthening the political function of jurisprudence is very important to improve the political status of jurisprudence, but under the political discourse, the jurisprudence discipline has not built a mature legal system of discourse. Therefore, when all sorts of questions about the rule of law proposition came to an end, people couldn't find any reason to argue against jurisprudence. In the study of this article, we attempted to analyze the drawbacks of the legislative-centered stance of jurisprudence teaching and research from the point of view of the construction of the rule of law in China, and further demonstrated the positive significance of the judicial center-centered stance to the construction of jurisprudence disciplines and the construction of the rule of law discourse system. 


\section{Jurisprudence Function of Judicial Position}

The judicial position here refers to the way of defending rights and justice up to the realization of the rule of law, or, in other words, applying the legal position. Judging from this perspective, jurisprudence is about the principles, principles, and methods of how the rule of law is realized. In this section we mainly describe what the basic function of Chinese jurisprudence should be. Jurisprudence is sometimes called legal philosophy. It is the study of general issues of law. In the research of many problems, it is the ultimate concern for the law. The impression that jurisprudence has left for many people is metaphysics. Many of the issues discussed are large and complex. Thus, the function and role of jurisprudence can be expressed from many perspectives. We cannot only see the political function of jurisprudence, but we should also pay attention to the legal function of jurisprudence. Although jurisprudence studies the general, essential, and value issues of law, the basic function of jurisprudence lies in the understanding of the use of legal essence, characteristics, and values. Therefore, the method of law application is an important aspect of jurisprudence. Since there are many forms of politics, including the rule of law politics, the autocratic politics, and the political means of mixing various means of governance, we cannot talk about the relationship between the rule of law and politics in general terms. However, because people have established opposition to autocracy and pursued values such as democracy, freedom, equality, and fairness in the pursuit of the rule of law, the law that jurists talk about is not about maintaining autocracy and maintaining power, but about rights and Freedom is effectively guaranteed and fully realized. Therefore, jurisprudence in the contemporary sense becomes how to realize the legal principles of freedom, equality, justice, human rights, and democracy. The basic function of jurisprudence is to promote the realization of socialist core values through legal methods. We have already seen that in today's political trend, the rule of law has become a symbol of political correctness. In China, the rule of law has also been used as the basic mode of modern politics (governing the country). Therefore, jurisprudence focuses on the realization of the rule of law. This of course does not mean that all jurisprudence serves the rule of law, and there have also been legal theories of authoritarian and authoritarian service in history. In China, the ancient legalist thought was to serve the imperial power, and the analysis of the law that "the law of evil is also law" also served as justification for the German fascist rule. However, these views cannot represent the main function of jurisprudence.

\section{Construction of Legal Discourse System}

China is undergoing a legal transformation of its governance approach. Therefore, the most important mission of contemporary Chinese jurisprudence is not to cater to the needs of the power order, but rather to demonstrate the theoretical basis for the construction of the rule of law in China and to shape the ideology of the rule of law so that the rule of law can be better Play the function of limiting power; use legal discourse to replace power discourse, and form legal ideology on the basis of legal discourse. After the central government proposed that the rule of law should be the basic mode of governing the country, Chinese jurisprudence should serve the rule of law and serve the rule of law. The use of the rule of law to resolve social contradictions needs to raise people's level of legal thinking, and jurisprudence can play an important role in this regard. If jurisprudence cannot serve the construction of the rule of law China, it will be separated from the needs of the real society, and it will also derive problems of birth and death. In 2016, Prof. Xu Aiguo of Peking University discussed the death of Chinese jurisprudence, and $\odot 27$ thought that jurisprudence in China does not have the foundation of Chinese culture and belongs to the "sand castle". In his eyes, jurisprudence basically belongs to political jurisprudence and is a political lesson for law students. Our research also found that some scholars only paid attention to the grafting of jurisprudence and political discourse, thus making the jurisprudence of the past more like politics; while another part of the scholars only paid attention to the absorption of Western jurisprudence and did not notice the convergence with Chinese culture. Professor Xu Aiguo asserted that Chinese jurisprudence may go "death." We do not deny the positive significance of this "survival to death." This criticism will make many of us realize the crisis of Chinese jurisprudence. However, we need to be alert to 
another kind of "death" method of Chinese jurisprudence - if many law students feel that jurisprudence is useless, it will also promote Chinese jurisprudence to "death." Although jurisprudence is a study of the general issues of law, studying the ontology, values, and methods of its realization, jurisprudence, like other laws, is where its vitality lies. The use of jurisprudence is manifested in two aspects: epistemological methods and methodological approaches to resolve disputes. The epistemological approach is mainly to help us avoid misunderstandings and to understand the law properly and comprehensively. The methodological approach to dispute resolution is to formulate specific solutions for dispute resolution based on correct understanding. But how can we establish a methodological jurisprudence that we can apply to study?

To build a legal discourse system, first of all, we should find the methodological propositions required for the realization of the law. There are many propositions of jurisprudence, but many propositions are borrowed from philosophy, politics, ethics, and logic. Learning from the original is an indispensable method for academic research. However, we need to identify these propositions. We cannot make the study of these propositions go to philosophy, political science, or ethics. When these propositions become a part of jurisprudence, they need to serve the argument of the rule of law. Such as objectivity, subjectivity, legitimacy, rationality, generality, systematism, acceptability, modifiableness, repealability, etc., we need to proceed from the requirements of the construction of the rule of law, based on the study of basic propositions, Construct a discourse system of jurisprudence serving as the rule of law. In this discourse system, it should include training on legal thinking and the promotion of the rule of law. In other words, jurisprudence serves the construction of the rule of law. In the various qualitative studies of law, the independence of the law is of great significance. Because the rule of law proposition can be established, and can be implemented in methodology, the relative independence of the law is the primary condition. Without relatively independent laws, there can be no "law" treatment at all. The precondition for "law" governance is that the "law" system can independently adjust social relations. Without legal independence, the rule of law is not only impossible, but it is still impossible to implement.

The legal system has a very important position in both the legislative and judicial process. In the judicial process, we often say that the violation of a legal norm is an illegal act, and the system interpretation rule is also called the golden rule of legal interpretation. The systematic factor of legal interpretation is an important way to understand the meaning of law. However, in the process of constructing the legal discourse system, our system thinking often has problems. Failure to promote the rule of law has become an obstacle to the realization of the rule of law. This is mainly due to the fact that our systemic thinking on legal issues is shaped by holistic thinking. The holistic thinking, based on the view that all things in the world are universally connected, opposes looking at issues in isolation and opposing one-sided thinking on matters. However, "discussing things on the matter" and "discussing the law on the matter" are precisely the characteristics of legal thinking or the use of the rule of law to resolve contradictions. Of course, discussing issues is not a simple legalism. It regards the legal provisions as the only basis for handling problems, but it is necessary to speak in terms of reasoning, to turn laws into grounds, and to use grounds as a law. The law is not a dry article. The true meaning of exploring the legal meaning lies in the "law in the matter." In the search for legal significance in the matter, people have found that systematic laws face two forms of closure and openness.

\section{Conclusion}

Because the law-centered doctrine overemphasizes the state's role in the creation and implementation of the law, it has increased the force of violence in law and the country has been described as a machine of violence. Law has become a tool for violence. From the perspective of political sociology, national violence does play an important role in the implementation of the law. The function of the law cannot be separated from the national coercive force. However, from the perspective of rule of law rhetoric or legal rhetoric, such a statement is not. Sensible. Because of the legal function of the law, values such as justice, human rights, freedom, and fairness are the "veil" that is covered by state violence. When it is torn apart, the law becomes naked violence. Laws are 
considered weapons. Therefore, in the legal instrumentalism or weapon theory, the struggle philosophy has a struggle for power, which leads to the absolute thinking of power, and the struggle for rights leads to the absolute of rights. Under the guidance of such a discourse system, it is difficult to Constructing the rationale for the rule of law needed for the construction of the rule of law in China, jurisprudence is useful, and both the administrator and the governed are able to apply the principles of the rule of law, which is the basis for thinking that the rule of law can be realized. The way of thinking, as long as we build a platform for the rule of law, we can approach the rule of law.

\section{References}

[1] Xie Hui. Jurisprudence can and can not [J]. Law, 2010, (12): 11.

[2] Du Yanlin, Miao Yan. Domestication Law: The basic mission of departmental legal philosophy [J]. Law Review, 2011, (6): 64.

[3] Qiu Ben. Again on the departmental legal philosophy [J]. Legal System and Social Development, 2010, (3): 3,5.

[4] Mizoguchi Yuzo. The common possibility of knowledge [J]. Reading, 1998, (2): 115.

[5] Sun Yuxi. Several issues concerning the study of the "departmental legal philosophy" in China [J]. Politics and Law, 2007, (6): 10 - 12. 